\title{
Tratamento anaeróbio de esgoto e sua eficiência na redução da viabilidade de ovos de helmintos
}

\author{
Helminth eggs and protozoan cysts in sludge obtained \\ by anaerobic digestion process
}

\section{Rosangela C. Paulino', Edilene A. Castro ${ }^{1}$ e Vanete Thomaz-Soccol ${ }^{1}$}

\begin{abstract}
Resumo O presente trabalho tem como objetivo determinar a prevalência e a viabilidade de ovos e larvas de helmintos e cistos de protozoários presentes em biossólido e em esgoto submetido ao tratamento anaeróbio em estações de tratamento de esgoto onde são empregados reatores anaeróbios de lodo fluidizado (RALF), na região metropolitana de Curitiba, Paraná. Os parasitos presentes no esgoto e no lodo foram helmintos: Ascaris $s p(85 \%)$, Toxocara $s p(5,5 \%)$, Trichuris $s p(4,5 \%)$, Hymenolepis diminuta $(3,7 \%), \mathrm{H}$. nana $(1 \%) e$ Taenia sp (0,4\%), Protozoários: Isospora sp, Entamoeba coli, Entamoeba histolytica, Giardia lamblia, Endolimax nana. Houve diferença significativa quanto ao número de ovos viáveis de helmintos presentes no material de quatro estações estudadas. A redução da viabilidade dos ovos de helmintos variou de 59,7 a $93 \%$. No tratamento biológico baseado na digestão anaeróbia a eficácia depende do tempo e da temperatura. Novos tratamentos higienizantes são necessários para a utilização do lodo produzido por digestão anaeróbia na reciclagem em agricultura ou para outros objetivos visando reduzir o risco para saúde humana e animal.
\end{abstract}

Palavras-chaves: Tratamento anaeróbio. Lodo fluido. Ovos de helmintos. Cistos de protozoários.

Abstract This study evaluates the prevalence and viability of helminth eggs and protozoan cysts in sludge obtained by anaerobic treatment in four treatment stations in Curitiba, Parana State, Brazil. The parasites observed were helminths: Ascaris $s p(85 \%)$, Toxocara $s p(5.5 \%)$, Trichuris $s p(4.5 \%)$, Hymenolepis diminuta $(3.7 \%)$, $\mathrm{H}$. nana (1\%) and Taenia sp (0.4\%), protozoan: Isospora sp, Entamoeba coli, Entamoeba histolytica, Giardia lamblia, Endolimax nana. In biological treatment based on the anaerobic digestion the effectiveness depends on the duration and temperature. The treatment showed efficiency for pathogen reduction of between 59.7 to $93 \%$. However, the number of helminth eggs found in treatment stations was still high and new higher performance treatment is necessary for land application or for other objectives, seeking to reduce the risks for human and animal health.

Key-words: Anaerobic digestion. Fluid sludge. Helminth ova. Protozoan cysts.

A atividade diária do homem gera vários resíduos. O esgoto doméstico é um deles. Este é coletado e tratado tendo como produtos resultantes o efluente e o sedimento denominado de biossólido. O efluente volta aos rios, porém, o sedimento gera um problema ligado ao seu destino final. Em virtude das dificuldades de dar um destino adequado ao sedimento resultante, vários países têm estudado possibilidades de disposição final como: incineração, aterros sanitários, disposição oceânica, produção de tijolos, recuperação de solos e uso em reciclagem agrícola. Trabalhos realizados em diferentes países demonstram que ele tem efeitos benéficos para o cultivo de vegetais, e tem sido aplicado em áreas de recreação, em jardins, em pastagens e florestas e em recuperação de áreas degradadas 58101317 .

$\mathrm{O}$ esgoto antes de passar por qualquer tipo de tratamento de estabilização e de higienização contém macro e micronutrientes e microrganismos. Muitos destes últimos são saprófitos e geralmente participam dos processos aeróbio e anaeróbio de estabilização. Porém, o esgoto oriundo de população humana e animal pode apresentar patógenos como bactérias, vírus, ovos e larvas de helmintos e cistos de protozoários parasitos.

O manuseio e o emprego de esgoto, para os mais variados fins, sem prévio tratamento de estabilização e sem tratamentos higienizantes possibilitam infecção do homem e dos animais ${ }^{3} 121319$. Em virtude disso, processos de tratamento de estabilização têm sido realizados em diversos países, inclusive no Brasil. Dentre os vários processos testados, os mais freqüentemente empregados para a estabilização de esgoto são a digestão aeróbia e anaeróbia. Tratamentos higienizantes do biossólido como uso de

1. Laboratório de Parasitologia do Departamento de Patologia Básica da Universidade Federal do Paraná, Curitiba, PR. Apoio financeiro: MCT/ PADCT, FINEP, SANEPAR

Endereço para correspondência: Dra. Vanete Thomaz Soccol. Centro Politécnico/UFPR, Jardim das Américas, 81531-990 Curitiba, PR Brasil. Fax : $5541266-2042$

e-mail:vasoccol@garoupa.bio.ufpr.br

Recebido em 8/9/2000. 
cal e compostagem também são preconizados e empregados por alguns países como Estados Unidos, França e Brasill 359161719212427 . A eficiência destes processos depende da qualidade operacional dos mesmos e da natureza dos patógenos presentes no lodo.

Pouco se conhece sobre a fauna helmíntica presente no esgoto e no biossólido resultante destes tratamentos. Além disso, o lodo acumulado nas estações em leito de secagem tem sido motivo de preocupação, pois caso apresente agentes patogênicos, poderá contaminar o solo e os rios, bem como ser fonte de infecção para as pessoas e animais que tenham contato com o mesmo. Tendo em vista essa preocupação, estudos têm sido realizados na região Metropolitana de Curitiba-Paraná, visando determinar os tipos de parasitas presentes no esgoto e no biossólido dele derivado, bem como a eficiência desinfectante dos diferentes processos de tratamento de esgoto 282930 . Um dos processos de estabilização do biossólido usado no Estado do Paraná é o sistema de Reatores Anaeróbios de Lodo Fluidizado (RALF) onde a estabilização ocorre devido ao tratamento anaeróbio. Porém, pouco se conhece sobre sua eficiência na redução de patógenos tais como bactérias, vírus, helmintos e protozoários.

No presente trabalho, foram estudadas a prevalência e a viabilidade de ovos e larvas de helmintos e cistos de protozoários no biossólido proveniente de esgoto submetido ao tratamento anaeróbio, em estações de tratamento de esgoto, onde são empregados reatores anaeróbios de lodo fluidizado. A escolha de estudar ovos de helmintos foi devido ao fato destes serem altamente resistentes no meio ambiente ${ }^{18}$ e sua baixa dose infectante para o homem ${ }^{26}$.

\section{MATERIAL E MÉTODOS}

Amostras. Coleta e preservação: amostragem seguiu critérios indicados por Stien e Schwartzbrod ${ }^{22} 23$ e Schwartzbrod et $\mathrm{al}^{20}{ }^{21}$. Foram coletadas amostras de esgoto e de biossólido de quatro unidades compactas de estações de tratamento de esgoto pelo processo anaeróbio, denominados reatores anaeróbios de lodo fluidizado. Três destas estações estão situadas em bairros de Curitiba (RALF Xaxim, RALF Fazendinha, RALF Santa Felicidade) e a outra está localizada no município de Pinhais RALF Vila Tebas (área metropolitana próxima a Curitiba ). Dos quatro RALFS foram coletadas cinco amostras (compostas) de esgoto e cinco amostras (compostas) de biossólido durante um período de 5 meses (Abril a Agosto de 1996), sendo coletada uma amostra composta, por mês, de cada um deles. As amostras de esgoto e de biossólido foram coletadas em frascos de um litro. Imediatamente após a coleta, o material foi transportado para o laboratório, em caixa de isopor contendo gelo (temperatura de $4^{\circ} \mathrm{C}$ ).

Determinação do número de ovos viáveis de helmintos. O método utilizado para a verificação da presença de ovos de helmintos em esgoto e no biossólido de esgoto foi o de Yanko, 1987 modificado 3031 .

Resumidamente, a análise consiste em pesar $50 \mathrm{~g}$ do material sólido (biossólido) ou $400 \mathrm{ml}$ do efluente. As amostras eram homogeneizadas com solução tamponada (tampão fosfato) contendo tween 80 a $1 \%$. Após a diluição, o material era filtrado para remoção de partículas sólidas e mantido a temperatura ambiente, por 12 horas, para sedimentar. O sobrenadante era retirado com auxílio de sifão e o sedimento resultante era transferido para tubos de centrífuga $(100 \mathrm{ml})$ e submetido a centrifugação a 3.500rpm, por três minutos. O sedimento resultante era ressuspenso em solução de sulfato de zinco com densidade 1,20 (v/v) e centrifugado a 3.500rpm, por três minutos. O sobrenadante era transferido para um erlenmeyer e o conteúdo era diluído à metade da concentração com água destilada. O material era então coberto com papel alumínio e deixado para sedimentar por três horas. Após o período de sedimentação, o sobrenadante era aspirado (o máximo possível) com auxílio de sifão e o sedimento ressuspenso por agitação. $O$ material resultante $(50 \mathrm{ml})$ era transferido para tubos cônicos de centrífuga. $O$ bequer era lavado para retirar eventuais ovos que tivessem ficado aderidos à sua parede. Centrifugavase o material a $1.400 \mathrm{rpm}$ por três minutos. Após centrifugação, o sedimento resultante era agrupado em um único tubo, centrifugava-se novamente a $1.400 \mathrm{rpm}$, e o sedimento era ressuspenso em solução ácido/álcool - éter etílico $\left(\mathrm{H}_{2} \mathrm{SO}_{4} 0,1 \mathrm{~N} / \mathrm{C}_{2} \mathrm{H}_{5} \mathrm{OH} 35 \%\right)$ $(7 \mathrm{ml} / 3 \mathrm{ml})$. Agitava-se a solução no tubo e este era aberto a cada agitação para deixar escapar o gás. Centrifugava-se a 1.800 rpm, por 3 minutos. Descartava-se o sobrenadante. Para eliminar o éter era procedido uma nova lavagem do material com $4 \mathrm{ml}$ de $\mathrm{H}_{2} \mathrm{SO}_{4} 0,1 \mathrm{~N}$. Descartar novamente o sobrenadante e finalmente, o sedimento era ressuspenso em $4 \mathrm{ml}$ de solução $0.1 \mathrm{~N}$ de $\mathrm{H}_{2} \mathrm{SO}_{4}$. Parte dele $(1 \mathrm{ml}$ ) era usado para determinação do número de ovos de helmintos ou de cistos de protozoários em câmara de SedgwickRafter. A outra parte era incubada em estufa a $28^{\circ} \mathrm{C}$ por quatro semanas para o estudo da viabilidade dos ovos de helmintos. O sedimento era ressuspenso de tempo em tempo e o tubo era aberto para oxigenação. No decorrer do trabalho foi feita a opção por ler os $4 \mathrm{ml}$ após o período de incubação de quatro semanas. O resultado é expresso em número de ovos ou de cistos 
por grama de matéria seca. Para isso era realizado concomitantemente o peso seco. A porcentagem de umidade é determinada como na metodologia analítica: em uma amostra separada (10 ou $50 \mathrm{~g}$ coloca-se em estufa a temperatura de $110^{\circ} \mathrm{C}$ até peso constante) para uso do cálculo final de ovos por grama de matéria seca. A viabilidade dos mesmos foi determinada por meio de observação microscópica, para verificação da presença de larva e de sua motilidade no interior do ovo ${ }^{1011} 163031$.

\section{RESULTADOS}

Ovos de helmintos e cistos de protozoários estiveram presentes em todas as análises realizadas. Foram encontrados ovos de helmintos pertencentes às superfamílias Ascaroideae e Trichuroidea e famílias Taeniidae e Hymenolepididae. No caso dos ovos de parasitos pertencentes aos Ascaroidea alguns deles podem ser semelhantes como Ascaris lumbricoides/ A. suum e Toxocara canis/ T. catti e como ambos poderiam estar presentes no biossólido analisado foi feita a opção por citar apenas o gênero. Da mesma forma, pelo ovo é impossível distinguir Taenia solium e T. saginata, além do que poderiam estar presentes ovos de outros teniideos de cães e gatos ( $T$. hidatigena, T. serialis, Hidatigera taenuiformis); por esta razão, os resultados referem-se a Taenia sp. A seguir, os dados obtidos são apresentados por estação de tratamento.
RALF Vila Tebas. Esgoto: a fauna parasitária encontrada foi: Ascaris sp, Trichuris sp, Toxocara $s p$, e Enterobius vermicularis, Hymenolepis nana, $H$. diminuta. Ovos de Ascaris sp foram encontrados em $100 \%$ das amostras analisadas, com porcentagem de viabilidade de 58,8\% (Tabela 1). Quanto aos protozoários, foram observados cistos de Entamoeba coli na média de dois cistos por litro de esgoto.

Biossólido: a fauna parasitária foi a mesma do esgoto mas acrescida de ovos de Taenia sp (Tabela 2). Os cistos de protozoários presentes foram: Isospora sp (2 cistos/litro), Entamoeba coli (28/litro), Entamoeba histolytica (4/litro), Giardia lamblia (14 cistos/litro) e Endolimax nana (4 cistos/litro).

Tabela 1 - Número de ovos de helmintos por litro de esgoto encontrados em reator anaeróbio de lodo fluidizado da estação de tratamento Vila Tebas.

\begin{tabular}{|c|c|c|c|c|c|c|c|c|}
\hline \multirow{3}{*}{$\begin{array}{l}\text { Parasitas } \\
\text { № de ovos/litro }\end{array}$} & \multicolumn{5}{|c|}{ Mês/ano } & \multirow{3}{*}{$\begin{array}{l}\text { № } \\
\text { médio/l }\end{array}$} & \multirow{3}{*}{$\begin{array}{l}\% \\
\text { viab* }\end{array}$} & \multirow{3}{*}{$\begin{array}{l}\text { № ovos } \\
\text { viáveis/l }\end{array}$} \\
\hline & $a b r / 96$ & mai/96 & jun/96 & $\mathrm{jul} / 96$ & ago/96 & & & \\
\hline & & & & & & & & \\
\hline Ascaris sp & 18 & 255 & 0,5 & 14 & 2 & 57,8 & 58,8 & 34 \\
\hline Trichuris trichiura & 0 & 0,5 & 0 & 1 & 0 & 0,3 & 50,0 & 0,15 \\
\hline T. vulpis & 0 & 0,5 & 0 & 0 & 0 & 0,1 & 100,0 & 0,1 \\
\hline Toxocara sp & 0 & 1,5 & 0 & 0 & 0 & 0,3 & 33,4 & 0,1 \\
\hline E. vermicularis & 2 & 0 & 0 & 0 & 0 & 0,4 & 0 & 0 \\
\hline H. nana & 0 & 4 & 0 & 0 & 0 & 0,8 & 0 & 0 \\
\hline H. diminuta & 0 & 1 & 0 & 0 & 0 & 0,2 & 0 & 0 \\
\hline Total & 20 & 263 & 0,5 & 15 & 2 & 59,9 & $34,6^{*}$ & 34,35 \\
\hline
\end{tabular}

* viabilidade média dos diferentes parasitas encontrados

Tabela 2 - Número de ovos de helmintos por litro de biossólido encontrados em reator anaeróbio de lodo fluidizado da estação de tratamento Vila Tebas.

\begin{tabular}{|c|c|c|c|c|c|c|c|c|}
\hline \multirow{3}{*}{$\begin{array}{l}\text { Parasitas } \\
\text { № de ovos/litro }\end{array}$} & \multicolumn{5}{|c|}{ Mês/ano } & \multirow{3}{*}{$\begin{array}{l}\text { № } \\
\text { médio/l }\end{array}$} & \multirow{3}{*}{$\begin{array}{l}\% \\
\text { viab* }\end{array}$} & \multirow{3}{*}{$\begin{array}{l}\text { № ovos } \\
\text { viáveis/l }\end{array}$} \\
\hline & $\mathrm{abr} / 96$ & mai/96 & jun/96 & jul/96 & ago/96 & & & \\
\hline & & & & & & & & \\
\hline Ascaris $s p$ & 1460 & 46 & 712 & 234 & 606 & 611 & 44 & 268 \\
\hline T. trichiura & 32 & 2 & 10 & 11,3 & 24 & 16 & 20 & 3,0 \\
\hline T. vulpis & 7 & 0 & 4 & 5,3 & 8 & 5 & 26 & 1,3 \\
\hline Toxocara sp & 16 & 6 & 15 & 4,6 & 62 & 21 & 32,2 & 4,8 \\
\hline Taenia sp & 6 & 0 & 12 & 0 & 1 & 0,8 & 77 & 0,6 \\
\hline H. nana & 2 & 0,6 & 0,6 & 0 & 0 & 0,6 & 33,4 & 0,2 \\
\hline H. diminuta & 13 & 9,6 & 12,7 & 4,6 & 105 & 29 & 49,2 & 14,3 \\
\hline Total & 1536 & 64,2 & 766,3 & 259,9 & 806 & 683,4 & $40,25^{\star}$ & 292,2 \\
\hline
\end{tabular}

* viabilidade média dos diferentes parasitas encontrados 
RALF Padilha. Esgoto: a fauna parasitária encontrada foi: Ascaris sp, Trichuris trichiura, T. vulpis, Toxocara sp, Hymenolepis diminuta, H. nana, Taenia sp. Ascaris representou $81,97 \%$ dos ovos de helmintos com $59 \%$ de viabilidade (Tabela 3 ). Taenia sp representou $0,8 \%$ dos ovos de helmintos e com $100 \%$ de viabilidade. Os cistos de protozoários presentes foram: E. coli (16/litro), G. lamblia (12 cistos/litro de esgoto).

Biossólido: a fauna parasitária encontrada foi Ascaris sp, representando $84,5 \%$ dos ovos de helmintos, T. trichiura, T. vulpis, Toxocara sp, H. nana e $H$. diminuta (Tabela 4). Ascaris lumbricoides teve um percentual de $38,7 \%$ de viabilidade. Cistos de protozoários presentes foram: E. coli (36/litro de biossólido) Isospora sp (4 cistos/litro).

RALF Itatiaia. Esgoto: a fauna parasitária encontrada foi: Ascaris sp, Trichuris sp, Toxocara sp, Hymenolepis nana, H. diminuta e Taenia sp. Nas cinco amostras analisadas, Ascaris representou $43,7 \%$ da fauna parasitária e Toxocara sp $25 \%$, ambos com $50 \%$ de ovos viáveis (Tabela 5).

Tabela 3 - Número de ovos de helmintos por litro de esgoto encontrados em reator anaeróbio de lodo fluidizado da estação de tratamento Padilha.

\begin{tabular}{|c|c|c|c|c|c|c|c|c|}
\hline \multirow[b]{2}{*}{ Parasitas } & \multicolumn{5}{|c|}{ Mês/ano } & \multirow[b]{2}{*}{ № } & \multirow[b]{2}{*}{$\%$} & \multirow[b]{2}{*}{ № ovos } \\
\hline & $\overline{\mathrm{abr} / 96}$ & mai/96 & jun/96 & jul/96 & ago/96 & & & \\
\hline № de ovos/litro & 96 & 6 & & & 6 & médio/l & viab* & viáveis/l \\
\hline Ascaris sp & 0 & 18,5 & 0 & 1 & 76 & 19,1 & 59 & 11,2 \\
\hline T. trichiura & 0 & 0,5 & 0 & 1 & 4 & 1,1 & 8,34 & 0,1 \\
\hline T. vulpis & 0 & 0 & 0 & 0 & 1 & 0,2 & 0 & 0 \\
\hline Toxocara sp & 0 & 3,5 & 0 & 0 & 0 & 0,7 & 14,3 & 0,1 \\
\hline H. nana & 0 & 0,5 & 0 & 0 & 0 & 0,1 & 0 & 0 \\
\hline H. diminuta & 0 & 8 & 0,5 & 1 & 0 & 1,9 & 5,54 & 0,1 \\
\hline Taenia sp & 0 & 0,5 & 0,5 & 0 & 0 & 0,2 & 100 & 0,2 \\
\hline$\overline{\text { Total }}$ & 0 & 31,5 & 1,0 & 3 & 81 & 23,3 & 26,74 & 11,7 \\
\hline
\end{tabular}

* viabilidade média dos diferentes parasitas encontrados

Tabela 4 - Número de ovos de helmintos por litro de biossólido encontrados em reator anaeróbio de lodo fluidizado da estação de tratamento Padilha.

\begin{tabular}{|c|c|c|c|c|c|c|c|c|}
\hline \multirow[b]{2}{*}{$\begin{array}{l}\text { Parasitas } \\
\text { № de ovos/litro }\end{array}$} & \multicolumn{5}{|c|}{ Mês/ano } & \multirow[b]{2}{*}{$\begin{array}{l}\text { № } \\
\text { médio/l }\end{array}$} & \multirow[b]{2}{*}{$\begin{array}{l}\% \\
\text { viab* }\end{array}$} & \multirow[b]{2}{*}{$\begin{array}{l}\text { № ovos } \\
\text { viáveis/l }\end{array}$} \\
\hline & $\mathrm{abr} / 96$ & mai/96 & jun/96 & $\mathrm{jul} / 96$ & ago/96 & & & \\
\hline Ascaris sp & 258 & 224 & 173 & 210 & 613 & 295,6 & 38,7 & 114,4 \\
\hline T. trichiura & 3,5 & 0,5 & 2,6 & 0 & 3 & 1,9 & 3,6 & 0,07 \\
\hline T. vulpis & 2,5 & 0 & 0 & 2 & 7 & 2,3 & 38,0 & 0,9 \\
\hline Toxocara sp & 3,5 & 40 & 2 & 17 & 38 & 22,1 & 24,4 & 5,4 \\
\hline H. nana & 0 & 11 & 0 & 0 & 2 & 0,5 & 50,0 & 0,25 \\
\hline H. diminuta & 0 & 0 & 0 & 62 & 34 & 21,4 & 57,6 & 12,3 \\
\hline Taenia sp & 0 & 0,5 & 0 & 0 & 0 & 0,1 & 50,0 & 0,05 \\
\hline $\begin{array}{l}\text { Total } \\
\end{array}$ & 267,5 & 276 & 177,6 & 291 & 697 & 343.9 & 34,33 & 133,37 \\
\hline
\end{tabular}

* viabilidade média dos diferentes parasitas encontrados

Tabela 5 - Número de ovos de helmintos por litro de esgoto encontrados em reator anaeróbio de lodo fluidizado da estação de tratamento Itatiaia.

\begin{tabular}{llllllllll}
\hline & \multicolumn{7}{c}{ Mês/ano } & & \\
Parasitas & № de ovos/litro & abr/96 & mai/96 & jun/96 & jul/96 & ago/96 & $\begin{array}{l}\text { № } \\
\text { médio/l }\end{array}$ & $\begin{array}{l}\text { N } \\
\text { viab* }\end{array}$ & $\begin{array}{l}\text { № ovos } \\
\text { viáveis/l }\end{array}$ \\
\hline Ascaris sp & 0 & 2,5 & 1 & 0 & 0 & 0,7 & 50 & 0,35 \\
T. trichiura & 0 & 0 & 0,5 & 0 & 0 & 0,1 & 100 & 0,1 \\
Toxocara sp & 0 & 0 & 0 & 0 & 2 & 1,6 & 50 & 0,8 \\
H. nana & 0 & 0,5 & 0 & 0 & 0 & 0,1 & 0 & 0 \\
H. diminuta & 0 & 0,5 & 0,5 & 0 & 0 & 0,2 & 0 & 0 \\
Taenia sp & 0 & 0,5 & 0 & 0 & 0 & 0,1 & 100 & 0,1 \\
\hline Total & 0 & 4 & 2 & 0 & 2 & 2,9 & 50 & 1,35
\end{tabular}

* viabilidade média dos diferentes parasitas encontrados 
Os cistos de protozoários encontrados foram E. coli com 16 cistos por litro.

Biossólido: a fauna parasitária presente foi: Ascaris sp, Trichuris trichiura, T. vulpis, Toxocara $s p$, Hymenolepis nana, $H$. diminuta, e Taenia sp. Ovos de Ascaris sp foram prevalentes com $87,1 \%$ e com $22,2 \%$ de viabilidade (Tabela 6 ).
Cistos de protozoários também foram observados com prevalência para $E$. coli (19 cistos por litro).

RALF Nova Orleans. Esgoto: em apenas uma de cinco amostras foram observados ovos de Ascaris sp, com 0,2 ovos por litro de esgoto analisado. Nenhum cisto de protozoários foi observado (Tabela 7).

Tabela 6 - Número de ovos de helmintos por litro de biossólido encontrados em reator anaeróbio de lodo fluidizado da estação de tratamento Itatiaia.

\begin{tabular}{|c|c|c|c|c|c|c|c|c|}
\hline \multirow{3}{*}{$\begin{array}{l}\text { Parasitas } \\
\text { № de ovos/litro }\end{array}$} & \multicolumn{5}{|c|}{ Mês/ano } & \multirow{3}{*}{$\begin{array}{l}\text { № } \\
\text { médio/l }\end{array}$} & \multirow{3}{*}{$\begin{array}{l}\% \\
\text { viab* }\end{array}$} & \multirow{3}{*}{$\begin{array}{l}\text { № ovos } \\
\text { viáveis/l }\end{array}$} \\
\hline & $a b r / 96$ & mai/96 & jun/96 & $\mathrm{jul} / 96$ & ago/96 & & & \\
\hline & & & & & & & & \\
\hline Ascaris sp & 4 & 190 & 18,7 & 1 & 62 & 22,14 & 22,2 & 12,24 \\
\hline T. trichiura & 0 & 6 & 0,3 & 0 & 1 & 1,4 & 0 & 0 \\
\hline T. vulpis & 0 & 2 & 1 & 2,5 & 3 & 1,7 & 37,5 & 0,64 \\
\hline Toxocara sp & 0 & 4 & 2 & 0 & 7 & 2,6 & 12,5 & 0,32 \\
\hline H. nana & 0 & 2 & 1,4 & 0 & 2 & 1 & 33,4 & 0,33 \\
\hline H. diminuta & 0 & 2 & 0,7 & 0 & 2 & 0,9 & 66,6 & 0,6 \\
\hline Taenia sp & 0 & 1,5 & 0 & 0 & 0 & 0,4 & 100,0 & 0,4 \\
\hline Total & 4 & 207,5 & 24,1 & 3,5 & 77 & 30,14 & 38,85 & 14,53 \\
\hline
\end{tabular}

* viabilidade média dos diferentes parasitas encontrados

Tabela 7 - Número de ovos de helmintos por litro de esgoto encontrados em reator anaeróbio de lodo fluidizado da estação de tratamento Nova Orleans.

\begin{tabular}{|c|c|c|c|c|c|c|c|c|}
\hline \multirow{3}{*}{$\begin{array}{l}\text { Parasitas } \\
\text { № de ovos/litro }\end{array}$} & \multicolumn{5}{|c|}{ Mês/ano } & \multirow{3}{*}{$\begin{array}{l}\text { № } \\
\text { médio/l }\end{array}$} & \multirow{3}{*}{$\begin{array}{l}\% \\
\text { viab* }\end{array}$} & \multirow{3}{*}{$\begin{array}{l}\text { № ovos } \\
\text { viáveis/ }\end{array}$} \\
\hline & $a b r / 96$ & mai/96 & jun/96 & jul/96 & ago/96 & & & \\
\hline & & & & & & & & \\
\hline Ascaris $s p$ & 0 & 0 & 0 & 0 & 1 & 0,2 & 0 & 0 \\
\hline T. trichiura & 0 & 0 & 0 & 0 & 0 & 0 & 0 & 0 \\
\hline Toxocara sp & 0 & 0 & 0 & 0 & 0 & 0 & 0 & 0 \\
\hline H. nana & 0 & 0 & 0 & 0 & 0 & 0 & 0 & 0 \\
\hline H. diminuta & 0 & 0 & 0 & 0 & 0 & 0 & 0 & 0 \\
\hline Taeniasp & 0 & 0 & 0 & 0 & 0 & 0 & 0 & 0 \\
\hline Total & 0 & 0 & 0 & 0 & 1 & 0,2 & 0 & 0 \\
\hline
\end{tabular}

* viabilidade média dos diferentes parasitas encontrados

Tabela 8 - Número de ovos de helmintos por litro de biossólido encontrados em reator anaeróbio de biossólido fluidizado da estação de tratamento Nova Orleans.

\begin{tabular}{|c|c|c|c|c|c|c|c|c|}
\hline \multirow{3}{*}{$\begin{array}{l}\text { Parasitas } \\
\text { № de ovos/litro }\end{array}$} & \multicolumn{5}{|c|}{ Mês/ano } & \multirow{3}{*}{$\begin{array}{l}\text { № } \\
\text { médio/l }\end{array}$} & \multirow{3}{*}{$\begin{array}{l}\% \\
\text { viab* }\end{array}$} & \multirow{3}{*}{$\begin{array}{l}\text { № ovos } \\
\text { viáveis/l }\end{array}$} \\
\hline & $\overline{a b r / 96}$ & mai/96 & jun/96 & $\mathrm{jul} / 96$ & $\overline{a g o / 96}$ & & & \\
\hline & & & & & & & & \\
\hline Ascaris sp & 1 & 24 & 10 & 17 & 51 & 20,6 & 17,3 & 3,56 \\
\hline T. trichiura & 0,5 & 2,6 & 0 & 1 & 7 & 2,2 & 0 & 0 \\
\hline Toxocara sp & 0 & 0 & 6 & 0 & 1 & 2 & 25,0 & 0,5 \\
\hline H. nana & 0 & 2 & 0 & 1 & 1 & 0,8 & 0 & 0 \\
\hline H. diminuta & 0 & 0 & 4 & 0 & 0 & 0 & 0 & 0 \\
\hline Taenia sp & 0 & 0 & 0 & 0 & 0 & 0 & 0 & 0 \\
\hline Total & 1,5 & 8,6 & 20 & 19 & 60 & 25,6 & 7,0 & 4,06 \\
\hline
\end{tabular}

* viabilidade média dos diferentes parasitas encontrados 
Biossólido: a fauna parasitária encontrada foi: Ascaris sp, Trichuris trichiura, T. vulpis, Enterobius vermicularis, Toxocara sp, Hymenolepis nana, $H$. diminuta, e Taenia sp. Ovos de Ascaris sp foram encontrados em $100 \%$ das amostras analisadas representando $80 \%$ da fauna parasitária encontrada e com 17,3\% de viabilidade (Tabela 8 ). Cistos de protozoários foram observados na média de 8 cistos por litro de biossólido.
Com relação ao parasito prevalente, sem sombra de dúvida, Ascaris sp foi o mais freqüente em todas as estações de tratamento. Os ovos deste parasito têm membranas espessas e podem sobreviver no ambiente por períodos variáveis de um a sete anos ${ }^{14}$ podendo chegar a 10 anos $^{5}$. Ovos de Taenia sp estavam presentes nos quatro RALFs analisados, apresentando maior índice no RALF Vila Tebas (até 12 ovos por litro - Tabela 2) e representou em média $0,4 \%$ dos ovos observados.

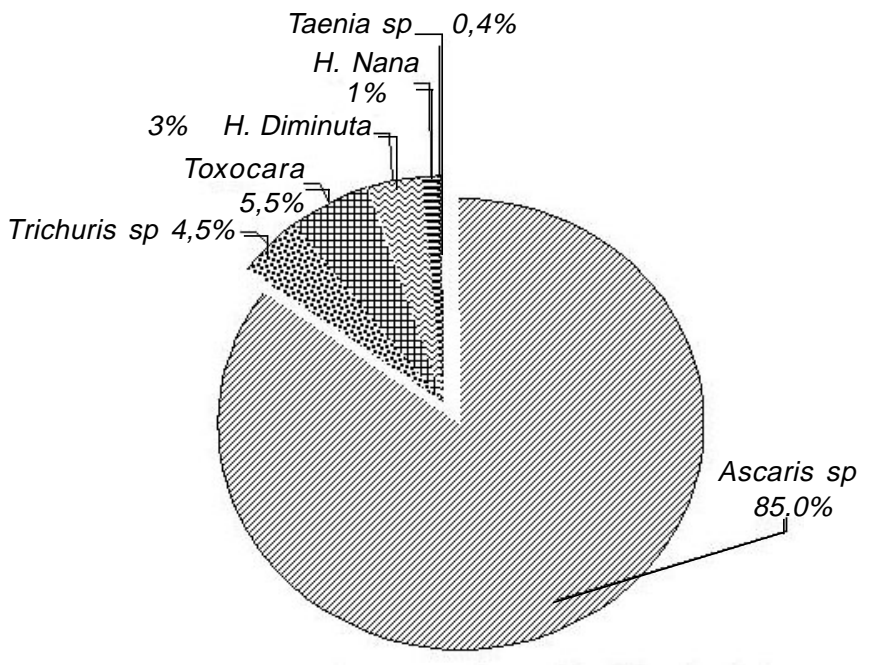

Figura 1 - Principais ovos de helmintos encontrados em biossólido oriundo de tratamento por digestão anaeróbia. Os resultados apresentam a média aritmética dos dados obtidos em quatro reatores de lodo fluidizado estudados na região metropolitana de Curitiba, Paraná.

\section{DISCUSSÃO}

Biossólido resultante de tratamento por processo de digestão anaeróbia foi analisado em quatro estações de tratamento da região Metropolitana de Curitiba. $O$ resultado de cinco repetições em cada RALF demonstra que ovos de nematóides prevaleceram sobre os de cestóides. Ascaris sp foi o parasita prevalente em todos os RALFs estudados e superando $85 \%$ do total de ovos viáveis, o que reflete o parasitismo da população humana ${ }^{7}$. Ovos de Taenias sp estiveram presentes em todos os RALFs estudados, embora em pequeno percentual.

Houve diferença significativa quanto ao número de ovos viáveis de helmintos presentes no material das quatro estações. Enquanto o RALF Vila Tebas apresentou elevado número de ovos de helmintos, no RALF Nova Orleans este número foi reduzido. A porcentagem de viabilidade dos ovos também variou de um RALF para outro (40,2\% para o RALF Vila Tebas e $7 \%$ para o RALF Nova Orleans). Nos quatro RALFs o percentual de redução da viabilidade destes ovos variou de 59,7 a 93\%. Estas diferenças poderiam ser explicadas, em primeiro lugar pelo número de habitantes em cada região, em segundo lugar, pela situação sócio-econômica dos habitantes dos bairros onde estes RALFS estão situados e enfim pelas condições operacionais dos mesmos ${ }^{13}{ }^{19}$. Isto pode ser observado quando comparados os RALFS de regiões distintas do município de Curitiba. O número total de ovos viáveis no RALF Vila Tebas foi de 292,2 por litro que indica necessidade de tratamento de higienização do mesmo para posterior utilização na agricultura ou para outros fins. Provavelmente, um inquérito parasitológico nas populações atendidas por estas estações de tratamento corroboraria estes resultados.

Nos Estados Unidos, o órgão de controle sanitário do esgoto e produtos dele derivados, a Agência de Proteção Ambiental (EPA) ${ }^{9}$, estabelece como padrão aceitável um número igual ou inferior a um ovo viável de helmintos por quatro gramas de matéria seca para que o biossólido seja usado para os mais variados fins. Dentro destes padrões, os biossólidos oriundos dos RALFS Nova Orleans e Itatiaia, com número de ovos de helmintos inferior àquele recomendado 
pela EPA, poderiam ser enquadrados nesta referida categoria. Porém, os biossólidos dos RALFS Padilha e Vila Tebas, submetido ao mesmo processo de tratamento, apresentaram número de ovos viáveis de 10 e 5 vezes superior ao recomendado indicando que devem ser submetidos a posterior tratamento de higienização (calagem ou compostagem) para posterior utilização.

No Brasil, estudos visando a utilização deste biossólido para aproveitamento como adubo orgânico na agricultura são ainda recentes. No Estado do Paraná, um projeto constituído por 11 subprojetos e com 10 anos de trabalho tem se prestado a este fim $^{12}$. Recentemente foi lançada norma de uso para 0 Estado do Paraná1.

No tratamento biológico baseado na digestão anaeróbia, a frio, a eficácia depende do tempo e da temperatura. Em média a eficácia na redução de patógenos em processos com temperatura de $20^{\circ} \mathrm{C}$ por 30 dias é de 60 a $75 \%$ dependendo da operabilidade do sistema de tratamento ${ }^{12} 17$. No presente trabalho, foi verificado uma variabilidade de redução de patógenos de 60 a 93\%. Porém, em regiões onde a população tem baixo padrão de saúde o número de ovos de helmintos presentes no biossólido é grande $(683,4$ ovos por litro) e mesmo o tratamento anaeróbio tendo uma eficiência média de $75 \%$ não é suficiente para reduzir o número de ovos de helmintos a níveis aceitáveis. A quantidade de ovos viáveis no final do processo de tratamento deve ser levada em consideração caso se queira utilizar o biossólido resultante na agricultura, em pastagens ou para outros fins.

Interessante observar que no Brasil, a partir dos anos 90, há um aumento da preocupação com o tratamento de esgoto e sua disposição final ${ }^{1} 213$. Buscando alternativas de disposição vários trabalhos têm sido realizados com a utilização do biossólido em agricultura, horticultura ou em pastagens ${ }^{2414}$. Para qualquer disposição final deve-se avaliar os riscos, pois este biossólido sem prévio tratamento higienizante, poderia colocar em risco direto a saúde da população humana e animal vivendo na área de utilização ou indiretamente populações que venham a consumir produtos vegetais oriundos destas áreas. Para a utilização deste biossólido deveriam ser criadas áreas de restrição de uso, como por exemplo, grandes áreas com culturas que sejam mecanizadas e em áreas que não sejam de mananciais.

Cabe ressaltar que outros patógenos além de ovos de helmintos devem ser pesquisados quando se visa a utilização do biossólido. Coliformes totais devem ser monitorados para verificar a possibilidade de recrescimento bacteriano. Salmonella $\mathrm{sp}^{15}$ e vírus entéricos ${ }^{20}$ também são parâmetros que devem ser incluídos para não colocar em risco a saúde humana e animal.

\section{AGRADECIMENTOS}

Os autores agradecem a Cleverson Andreoli (SANEPAR) pelo apoio e discussões, a Jerônymo Fernandes de Carvalho (SANEPAR) pela colaboração e a Juliana Tracks pelo auxílio técnico.

\section{REFERÊNCIAS BIBLIOGRÁFICAS}

1. Andreoli CV, Fernandes F, Domaszak S. Reciclagem Agrícola do biossólido de esgoto. Estudo preliminar para definição de critérios para uso agronômico e de parâmetros para normatização ambiental e sanitária, Companhia de Saneamento do Paraná, Curitiba, editora Companhia de Saneamento do Paraná (SANEPAR), 1997.

2. Andreoli CV, Souza MLP Comin JJ. Utilization of sludge from ETE BELEM for agricultural proposes. In: Symposium LusoBrazil of Sanitation and Environmental Engineering. Florianopolis,1964. Anais da Associação Brasileira de Engenharia Sanitária, Rio de Janeiro, p. 384-402,1995.

3. Barbier D, Perrine D, Duhamel C, Doublet R, Georges P. Parasitic hazard with sewage sludge applied to land. Applied and Environmental Microbiology 56:1420-1422, 1990.

4. Bertipaglia LMA, Vieira PF, Melo JV. Efeito do esgoto como componente da ração para bovinos em crescimento. In: Anais do I Seminário sobre gerenciamento de biossólidos do Mercosul, Curitiba, p.183-190, 1998.

5. Brudaston AN, Lemelev VR, Kholnukhanedov and Krasnos LN. The clinical picture of the migration phase of ascariosis in self-infection. Medskaya Parazitology 40:165-168,1971.
6. Carrington EG. The fate of pathogenic micro-organisms during waste-water treatment and disposal. Water Research Centre Technical report ํo 128: 58, 1980 .

7. Castro EA, Thomaz Soccol V, Hennig L, Paulino RC. Correlação entre prevalência de enteroparasitoses na população humana e a presença de patógenos no lodo de esgoto. In: Anais do I Seminário Nacional de Microbiologia Aplicada ao Saneamento. Vitória Espírito Santo 1:178-188, 2000.

8. Elissalde N, Ganiere JP, L'Hostis M, Legeas M, Demillac R, Carre J. Les germes pathogènes dans les boues résiduaires des stations d'épuration urbaines. Collection: Valorisation agricole des boues d'épuration. Guides et cahiers techniques, 1994.

9. Environmental Protection Agency (EPA). Control of pathogens and vector attraction in sewage sludge under 40CFR part 503. Office of Water, Office of Science and Technology Sludge Risk Assessment Branch. Washington, p. $147,1992$. 
10. Gaspard PG, Schwartzbrod J. Helminth eggs in wasterwater: quantification technique. Water Science and Technology 31:443-446, 1995.

11. Gaspard PG, Wiart J, Schwartzbrod J. A method for assessing the viability of nematode eggs in sludge. Environmental Technology 17:415-420, 1996.

12. Hays BD. Potential for parasitic disease transmission with land application of sewage plant effluents and sludges. Water Research 11:583-595,1977a.

13. Hays BD. Is there a potential for parasitic disease transmission from land application of sewage effluents and sludges? J.E.H. 39:424-426, 1977b.

14. Luduvice M. Experiência da Companhia de Saneamento do Distrito Federal na Reciclagem agrícola de biossólido. In: Bettiol Camargo (eds) Impacto ambiental do uso agrícola do lodo de esgoto, $1^{\text {a }}$ edição, Empresa Brasileira de Pesquisa- Meio Ambiente Jaguariúna, p. 245-258, 2000.

15. Medeiros ML, Thomaz Soccol V, Castro EA, Toledo EB, Borges JC, Paulino RC, Silva SM. Andraus S. Aspectos Sanitários. In: Andreoli C, Fernandes F (eds) Reciclagem de Biossólido/ Transformando Problemas em soluções. Companhia de Saneamento do Paraná (SANEPAR), CDD 628.36, Curitiba, p. 120-179, 1999.

16. Owen RR. The effectiveness of chemical disinfection on parasites in sludge. Stabilisation and Disinfection of Sewage Sludge 23:1-13, 1984.

17. Pike EB., Davis, RD. Stabilisation and disinfection -Their relevance to agricultural utilisation of sludge. Stabilisation and Disinfections of Sewage Sludge 3: 1-29, 1984.

18. Rey L. Parasitologia. $2^{a}$ edição Rio de Janeiro, Guanabara Koogan, 1991.

19. Rosaz, C. Risques sanitaires liés a l'épandage des boues de stations d'épuration. Application à la végetalisation des pistes de ski. Thèse de docteur Vétérinaire, soutenue le 11 juillet 1991 à l'Université Claude Bernard de Lyon. Ecole Nationale Vétèrinaire de Lyon,1991.

20. Schwartzbrod J, Mathieu C, Thevenot MT, Baradel JM, Schwartzbrod L. Analyse parasitologique et virologique des boues de station d'épuration. TMS - L'eau 81:149-153, 1986.

21. Schwartzbrod J, Mathieu C, Thevenot MT, Baradel JM, Schwartzbrod L. Sludge parasitological contamination. In: L'hermitte P (ed) Treatment and use of sewage sludge and liquid agricultural WASTES. Congress d'Athenes (GR), Elsevier Applied Science, 1990.

22. Stien JL. Schwartzbrod J. Flow of helminth eggs in activated sludge wastewater treatment plants. Technical Science Methods 83: 495-498, 1989.

23. Stien JL. Schwartzbrod J. Stratégie d'échantillonnage et dénombrement d' oeufs d'helminthes dans les boues résiduaires. Journal Français, 1989.

24. Thomaz-Soccol V, Aspectos sanitários do lodo de esgoto. Anais do I Seminário Sobre Gerenciamento de Biossólidos do Mercosul. Curitiba, p. 65-72, 1998.

25. Thomaz-Soccol V. Indicadores de Poluição/Métodos convencionais e moleculares de detecção. in: I Seminário Nacional de Microbiologia Aplicada ao Saneamento. Vitória, $1: 34-39,2000$

26. Thomaz-Soccol V, Paulino RC. Riscos de contaminação do agrossistema com parasitos pelo uso do lodo de esgoto. In: Bettiol, Camargo (eds) Impacto ambiental do uso agrícola do lodo de esgoto, 1a edição, Empresa Brasileira de Pesquisa-Meio Ambiente, Jaguariúna, p. 245-258, 2000.

27. Thomaz-Soccol V, Paulino RC, Castro EA. Eficácia dos diferentes processos de tratamento do lodo na redução da viabilidade de ovos de helmintos. SANARE 8:24-32,1997.

28. Thomaz-Soccol V, Paulino RC, Castro EA. Helminth eggs viability in sewage and biosolids sludge in Curitiba, Parana, Brazil. Brazilian Archives of Biology and Technology 40: 829836, 1997.

29. Thomaz-Soccol V, Paulino RC, Castro EA. Agentes Patogênicos: Helmintos e Protozoários em biossólido. In: Andreoli C, Fernandes F (eds) Reciclagem de biossólidos, Transformando problemas em soluções, Companhia de Saneamento do Paraná (SANEPAR), Curitiba 1999.

30. Thomaz-Soccol V, Paulino RC, Castro EA. Metodologia para análise parasitológica em lodo e em esgoto. In: Andreoli, Bonnet (eds) Manual para análises Microbiológicas e Parasitológicas em Reciclagem agrícola de lodo de esgoto. $2^{a}$ edição, Companhia de Saneamento do Paraná (SANEPAR), Curitiba, 2000.

31. Yanko W A, Ocurrence of pathogens in distribuition and marketing Municipal sludges. In: EPA Environmental regulation and technology. Control of pathogens and vector attraction in sewage sludge. Rapport U.S. EPA 625/R-92/013, p. 149, 1992. 